\title{
Some results of tritium researches of natural waters in Russia (1960-2010)
}

\author{
V. Soyfer ${ }^{1}$, V. Goryachev ${ }^{1}$, S. Vakulovsky ${ }^{2}$ and I. Katrich ${ }^{2}$ \\ ${ }^{1}$ Pacific Oceanological Institute of Far-Eastern Branch RAS, 690041 Vladivostok, RF \\ ${ }^{2}$ SI RPA "TYPHOON", Obninsk, RF
}

\begin{abstract}
Original data of tritium $\left({ }^{1} \mathrm{H}^{3} \mathrm{HO}\right.$, or HTO) studying (1959-2010) of both natural, and artificial (technogenic) origin in natural waters on the country territory and in the seas of the World Ocean are presented. Entry sources of cosmogenic and technogenic HTO in hydrosphere of the Earth from atmosphere and its carrying over to various links of hydrological cycle are considered. The basic laws of the spacetemporal HTO distribution in surface water of the northern part of the Eurasian continent, in the seas washing Russia and in separate water areas of the World Ocean, and also in atmospheric precipitation and Antarctica's firn snow are studied. Prevailing influence of a molecular exchange on the HTO content in the top layer of lakes, the seas and oceans and in atmospheric moisture over the ocean is shown. The theory of a multicomponent isotope balance method is developed for studying of dynamic characteristics of water objects. Priority results of tritium use in the industry (on oil deposits, collieries, mines etc.) and in researches under national and international programs (WESTPAK, SOUTHERN OCEAN, "Isotopes in deposits", the Soviet Arctic and Antarctic expeditions) are given. Systems of national and Far East regional monitoring HTO pollution of natural waters are created. Complexes for HTO measuring with record levels of threshold sensitivity (in the late seventies sensitivity of complex POI equaled to $4 \times 10^{-6} \mathrm{~Bq} / \mathrm{ml}$ ) have been developed.
\end{abstract}

\section{INTRODUCTION}

There is now a possibility to show consecutive development of authors works begun in "cold" war for the monitoring HTO and others radionuclide's, released at nuclear-weapon tests [1]. There was a necessity of expansion a network of points for sampling an atmospheric precipitation and aerosols and creation of the measuring centers for the analysis of samples delivered. It was clear to scientists the exclusive role of this isotope for the decision of applied problems with use the tritium indicator, so as powerful tool for fundamental studying the Earth natural waters circulation.

\section{DEVELOPMETNT OF METHODS FOR TRITIUM MEASUREMENT}

\subsection{Hardware-methodical bases for tritium measurement of natural waters}

\subsubsection{Laboratory installation for large-scale tritium measurements}

High-sensitivity equipment for registration of natural tritium with preliminary electrolytic enrichment has been created. It consisted of 3 steps electrolyzers (in everyone-5 electrolyzers) and low-level background Geiger-Muller counter made from electrolytic copper. Initial electrolyzer volumes of 1st, 2nd, 3rd stages make, accordingly, 3200, 500 and $16 \mathrm{ml}$; final - 110, 16 and 0.3-0.5 ml. Electrolyze time has been reduced and for 1st, 2nd and 3rd stages 70, 60 and 60 hours was made. Regeneration of enriched sample by the original for this purpose developed technique was spent. [1]. It consisted in 
Table 1. Comparative characteristics of systems of tritium registration gas proportional counters. $\left({ }^{*} \mathrm{C}_{\min }=\right.$ $2.77 \cdot \mathrm{F} \cdot(\mathrm{n} / \mathrm{t})^{1 / 2}, \mathrm{t}=1000 \mathrm{~min}$.)

\begin{tabular}{|l|c|c|c|c|c|c|}
\hline & $\begin{array}{c}\text { Volume of } \\
\text { counter (L) }\end{array}$ & Counting gas & $\begin{array}{c}\text { Pressure } \\
(\mathrm{atm})\end{array}$ & $\begin{array}{c}\mathrm{F}, \\
(\mathrm{TU} / \mathrm{cpm})\end{array}$ & $\begin{array}{c}\text { Background } \\
(\mathrm{cpm})\end{array}$ & $\begin{array}{c}\mathrm{C}_{\min } \\
(\mathrm{TU} .)\end{array}$ \\
\hline Soyfer (1971) [3] & 4.0 & $\mathrm{CH}_{4}$ & 2.5 & 9.54 & $3.8(\mathrm{ship})$ & 1.6 \\
\hline Ostlund (1975) & 2.2 & $\mathrm{H}_{2}+\mathrm{C}_{3} \mathrm{H}_{8}$ & $2+0.7$ & 44.0 & 1.0 & 3.90 \\
\hline Oeschger (1975) & 1.3 & $\mathrm{CH}_{4}$ & 1.33 & 72.0 & 0.08 & 1.80 \\
\hline Wolf (1981) & 2.2 & $\mathrm{C}_{3} \mathrm{H}_{8}$ & 2.0 & 23.2 & 0.48 & 1.40 \\
\hline Tishkov (1979) [5] & 8 & $\mathrm{C}_{6} \mathrm{H}_{10}$ & 1.5 & 11,9 & 4 & 2.1 \\
\hline POI FEB (1979) [1] & 4.0 & $\mathrm{CH}_{4}$ & 2.5 & 11.3 & 1.96 & 1.40 \\
\hline POI FEB 1997) [1] & 4.0 & $\mathrm{CH}_{4}$ & 5.5 & 5.2 & 2.60 & 0.66 \\
\hline
\end{tabular}

Increase of working pressure from 2.5 to $5.5 \mathrm{~atm}$ achievement of record value $\mathrm{C}_{\min }=0,66 \mathrm{TU}$ has provided, that exceeds in 2-3 times level of sensitivity $\mathrm{C}_{\min }$ reached in underground laboratories (Oeschger et al, 1975. Switzerland), (Wolf et al, 1981. Germany), (Tishkov et al, 1979).

application of nitrate lead as neutralizer:

$$
\begin{aligned}
& 2 \mathrm{KOH}+\mathrm{Pb}\left(\mathrm{NO}_{3}\right)_{2}=2 \mathrm{KNO}_{3}+\mathrm{Pb}(\mathrm{OH})_{2} \\
& \mathrm{~Pb}(\mathrm{OH})_{2} \rightarrow \mathrm{PbO}+\mathrm{H}_{2} \mathrm{O}
\end{aligned}
$$

Water loss at neutralizations and distillation thus did not surpass $3-4 \%$. The optimum of electrolyze conditions at which there is no corrosion of electrodes has been defined.

\subsubsection{Development a low-level background ship and stationary tritium measuring complexes}

The gap in some years between sampling at separate stations and their technological processing after delivery in coastal laboratories was the lack of tritium measurements, which spent, for example, under program WOCE. It excluded possibility of operative use tritium method at working on a sea.

The first successful experiment on HTO measurement has been made on board of R/V "Akademik Kurchatov" in 1971 [2]. The ship measuring laboratory, which structure practically was the same, but with autonomous electrolyzer cooling have been created in 1979 in POI [3, 4]. The system for preparation of a counting gas (methane) and HTO measurement was made. Methane from $19.5 \mathrm{ml}$ of water sample in presence of a zinc dust at $t=410-430^{\circ} \mathrm{C}$ and ruthenium the catalyst at $\mathrm{t}=500^{\circ} \mathrm{C}$ in one stage was synthesized. Reaction under the scheme results:

$$
\begin{aligned}
& \mathrm{H}_{2} \mathrm{O}+\mathrm{Zn}=\mathrm{ZnO}+\mathrm{H}_{2} \\
& \uparrow \quad \downarrow \\
& 2 \mathrm{H}_{2} \mathrm{O}+\mathrm{CH}_{4} \leftarrow \mathrm{CO}_{2}+\mathrm{H}_{2}
\end{aligned}
$$

The received value of background of $3.8 \mathrm{cpm}$ (in $1000 \mathrm{~min}$.) at methane pressure in the counter $2.5 \mathrm{~atm}$ allows registering HTO concentration $1.7 \mathrm{TU}$ with probability of $97.5 \%$ [2-4]. Use of two-stage electrolytic installation lowered minimum detected activity to $0.05 \mathrm{TU}$.

To improve a proportional method of HTO measurement the complex (the proportional counter with working volume 41 and powerful three-layer protection $-15 \mathrm{~T}$ ) has been created. In tritium window the background was lowered to $32.5 \mathrm{cpm}$., work of the basic counter with anticoincidence reduced a background to $1.96 \mathrm{cpm}$ [1]. Comparison of installations of POI parameters with ones of the best installations in our country and abroad resulted in Table 1. A limit direct (without enrichment) detection ${ }^{3} \mathrm{H}$ at routine measurements taking into account all errors $\mathrm{C}_{\min }=2.5 \mathrm{TU}$ [1-4]. 
Table 2. Results of definition of water exchange in ground waters basin of the Moskva- river.

\begin{tabular}{|l|c|c|c|c|c|}
\hline Research interval & \multirow{2}{*}{$\begin{array}{c}\text { Duration } \\
\text { imonth, year) }\end{array}$} & \multicolumn{2}{|c|}{ Tritium concentration, TU } & Rate of a \\
\cline { 3 - 5 } & & $\mathrm{T}_{1 \mathrm{r}}$ & $\mathrm{T}_{2 \mathrm{r}}$ & $\mathrm{T}_{\mathrm{p}}$ & $\begin{array}{c}\text { turn, } \\
\text { year }^{-1}\end{array}$ \\
\hline VI 1960-II 1961 & 0.75 & 40 & 55 & 135 & 0.265 \\
\hline VI 1960-IX 1961 & 1.21 & 40 & 48 & 115 & 0.125 \\
\hline II 1961-II 1962 & 1.00 & 55 & 80 & 170 & 0.295 \\
\hline II 1962-II 1963 & 1.00 & 80 & 200 & 1150 & 0.127 \\
\hline II 1963-VI 1963 & 0.33 & 200 & 230 & 1200 & 0.113 \\
\hline VI 1963-XII 1963 & 0.54 & 230 & 415 & 1300 & 0.320 \\
\hline I 1964-IX 1964 & 0.75 & 415 & 570 & 1400 & 0.245 \\
\hline I 1964-IX 1965 & 1.75 & 415 & 520 & 1100 & 0.125 \\
\hline VI 1963-IX 1965 & 2.30 & 230 & 520 & 1200 & 0.180 \\
\hline Mean & \multicolumn{4}{|l}{} & 0.195 \\
\hline
\end{tabular}

\section{RESULTS}

\subsection{Works of the period of nuclear tests and the first moratorium}

\subsubsection{The first measurements of natural tritium in ground waters, a method of estimation of their resources with use of box-models}

The first natural tritium measurement in our country in ground waters basin of the Moskva-river has been made in 1959 [6, 7]. To estimate stocks of surface and ground waters participated in a supplying the Moskva-river two models of ground waters have been considered: model with fast mixing of water in the reservoir (during full mixing by tritium disintegration it is possible to neglect) and model with absence of water mixing in the reservoir, where water movement was represented parallel to each other and a jet of water base [8].

For model with fast mixing of water and for variable tritium concentration $\mathrm{T}$, measured in an interval $\left(\mathrm{t}_{1}, \mathrm{t}_{2}\right)$ :

$$
C_{2}=C_{1} e^{-(\varepsilon+\lambda)\left(t_{2}-t_{1}\right)}+\frac{T \varepsilon}{\varepsilon+\lambda}\left(1-e^{-(\varepsilon+\lambda)\left(t_{2}-t_{1}\right)}\right)
$$

Here: $C_{1}$ - tritium concentration in the reservoir at the moment of time $\mathrm{t}_{1} ; \mathrm{C}_{2}$-at the moment of time $\mathrm{t}_{2}$ (it is measured $\mathrm{T}_{1}$ - tritium concentration in an atmospheric precipitation-supply source-at the moment $\mathrm{t}_{1} ; \mathrm{T}_{2}$ - the same for $\left.\mathrm{t}_{2}\right) ; \lambda-\mathrm{a}$ tritium disintegration constant $\left(0,055\right.$ year $\left.^{-1}\right) ; \varepsilon-$ rate of the reservoir turn, equal to the relation of an annual supply or a drain to volume of the reservoir (year ${ }^{-1}$ );

In model without mixing of water in the reservoir for variable tritium concentration, measured in an interval $\left(\mathrm{t}_{1}, \mathrm{t}_{2}\right)$

$$
C=\frac{\varepsilon}{\lambda}\left\{T_{0}\left(e^{-\lambda t}-e^{-\frac{\lambda}{\varepsilon}}\right)+\sum_{i=1}^{n-1} T_{i} e^{-\lambda\left(t-t_{i}\right)}\left[1-e^{-\lambda\left(t_{i}-t_{i-1}\right)}+T_{n}\left(1-e^{-\lambda t}\right)\right]\right\}
$$

The results received under formulas 3 and 4 differ a little. If the rate of water supplying $w$ (m/year) is known it is easy to find a capacity of the reservoir $\mathrm{V}$, which will made $\mathrm{w} / \varepsilon$. In Table 2 calculation of $\varepsilon$ according formula (3) is shown. The time of the ground waters turn is 5 years, their stock (at a difference deposits from evaporation $-300 \mathrm{~mm})-1,5 \mathrm{~m}$. 


\subsubsection{The multicomponent isotope balance method of studying of water objects dynamic characteristics $[9,10]$}

For the first time it was developed the method for finding of numerical characteristics of non-stationary processes of water exchange on the basis of use of stochasticity of variations of natural waters streams and their isotope versions ( $\mathrm{HTO},{ }^{1} \mathrm{H}^{2} \mathrm{HO}$, etc.) at input and output of the investigated system. Balance method developed earlier does not consider fluctuation of water and isotope flows, and also essential non stationary water exchange processes (a seasonal nature etc.). There are no also estimations of an error of stationary balance methods. The developed multicomponent isotope balance method can be extended practically to any hydrological, hydro-geological and other water systems on the basis of stochasticity of rain fall processes and formation of their isotope composition in any of supplying zones of a studied object. Each water object has an input jet (its parameters are measured), a water body which may be considered as "a black box" and an output jet, also measured. The input jet has the set area (water area) with the characteristic size for each water object. The method consists in sampling from water object and in the subsequent measurement of their isotope composition and comparison of parameters values on an input and an output of water object using developed algorithm. At such statement there is no need to enter functional model of studied system water exchange that makes a method more flexible and expands borders of its application. For the first time there were received such characteristics of water exchange, as flow time, transfer factors of influence of zones of supplying on sources, the components of a hydrograph used at estimation of degree of the water environment pollution danger and estimation of natural waters resources. The detailed description of a method is resulted in [1].

\subsubsection{Studying of tritium infiltration in surface water in water-bearing horizons of mountain constructions (mine, mines, open-cast mines)}

The results of pioneer works on water exchange of underground waters studying (within oil fields, coal and open -cast mines of deposits of iron ore) with HTO measurements in waters are shown. Tritium in atmospheric precipitation of that period served as a "bombing" time label [1].

\subsection{Studying of processes of tritium fields formation in atmosphere and hydrosphere}

\subsubsection{Check of neutrons release at "cold synthesis" (April-May 1989) [11]}

Recoil protons in a series of experiments on registration of a neutron release (energy 0.02-3 Mev), arising in the proportional counter (volume 4 1) were measured. Electrolyzer of $3^{\mathrm{d}}$ stage (see 2.1.1) with heavy water closely to a counter end face has been placed. The electrolyzer cathode plates or a wire in length of $9 \mathrm{sm}$ from examinees of materials (iron, stainless steel, the titan, vanadium, platinum, a palladium) were located between nickels plates (anode) into the glass container of $3 \mathrm{sm}$ in diameter with a solution sodium caustic in ${ }^{1} \mathrm{H}_{2} \mathrm{O}$ or ${ }^{2} \mathrm{H}_{2} \mathrm{O}(99.8 \%)$. Electrolyze was performed in a range of current density from 0.05 to $300 \mathrm{~A} / \mathrm{sm}^{2}$. The counter has been calibrated by the passported neutron source Cf -252 (its capacity equaled to $2 \times 10^{7} \mathrm{n} / \mathrm{c}$ ); efficiency of neutrons registration in the top channel (the bottom threshold $20 \mathrm{keV}$ ) was $7 \%$. Our system, allowing to measure a background neutron flux in "the top window", equal to $4 \times 10^{-2} \mathrm{n} / \mathrm{sec}$., has not registered the excess of the account over a background (account time in experience with a palladium - about 100 hours, reliability of a conclusion 0,999). It is $10^{16}$ less then value of a neutron flux by Fleishman and Ponse ostensibly measured. It was experimentally proved the absence in their experiment of endogen HTO source in ocean and reliably proved the concept of the developed methodology of tritium use in the oceanology, having only an atmospheric origin (neglecting local dumps of technogenic tritium has not registered).

\subsection{Tritium use in the researches under international program SOUTHERN OCEAN}

For the first time it was established the fact of a tritium penetration on depths over $1 \mathrm{~km}$ in the northern Atlantic on the range to the south from Iceland (autumn 1971 [2]). Later (1979-1980 [1]) in the North 


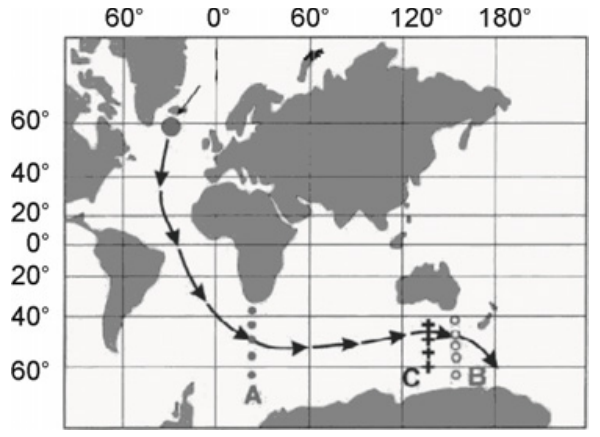

A - section along $20^{\circ} \mathrm{E}, 24$-th cruise $R V$ Professor Zubov, 1979

B - section along $162^{\circ}$ E, 26-th cruise $R V$ Professor Zubov, 1980;

C - section along $132^{\circ} \mathrm{E}$, RV Eltanin, 1970
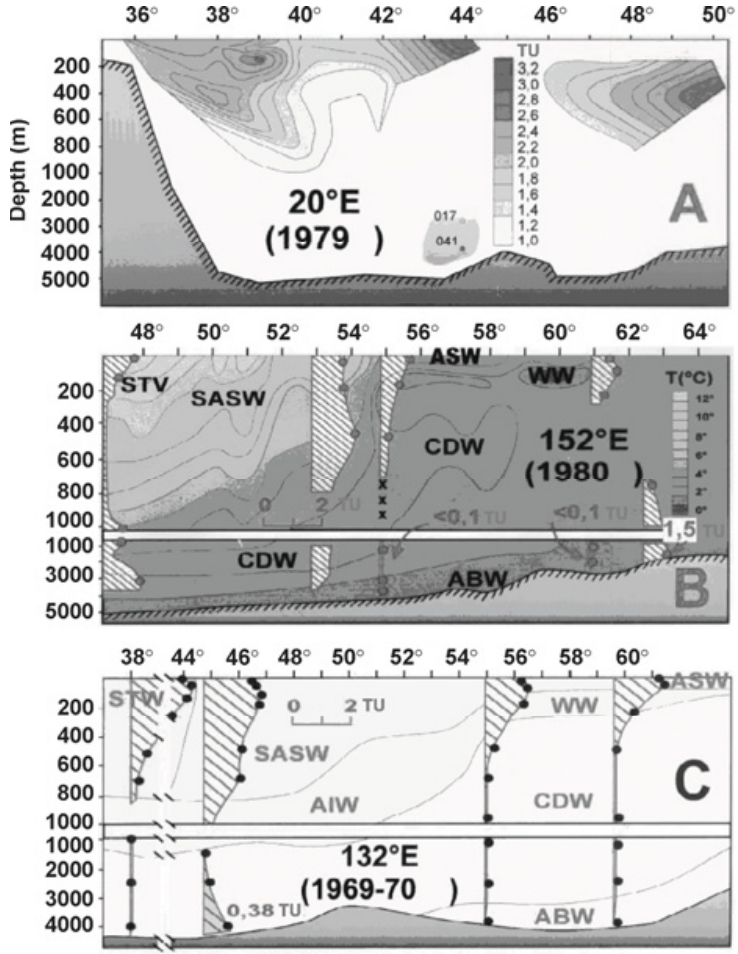

Figure 1. Tritium anomalies of "bomb" origin in the North Atlantic deep waters (NADW) of the African and Australian-New Zealand sectors. Ones are involved in the Antarctic Circumpolar currents (ACC). Here are: STW - Subtropics Water, AIW - Antarctic Intermediate Water, SASW - Sub Antarctic surface water, ASW - Arctic surface water, CDW - circumpolar Deep Water, ABW - Antarctic Bottom water, WW - Winter Water.

Atlantic deep waters (NADW) tritium anomalies (nearby 1TU) were found out and it was received the estimation of transport velocity (nearby $10 \mathrm{~cm} / \mathrm{s}$ ) NADW in the system of jet currents Antarctic Circumpolar (ACC, the project "Southern Ocean"). It exceeds tens times transfer velocity of the ACC deep waters, calculated by a dynamic method (fig. 1).

\subsection{Tritium monitoring of natural waters of Russia}

After carrying out of nuclear tests on New Zemlya (1962) and monitoring of radioactive fall out in extensive territory of the Eurasian part of the USSR, including tritium, work on creation of national system for the tritium monitoring of environments also has begun [12]. At present we have 30 points for sampling of natural waters. The data on tritium content in atmospheric precipitations from 18 points (originally all-union system tritium monitoring) were sent annually to WMO and IAEA.

\subsubsection{Tritium pollution monitoring of atmospheric precipitation, rivers and $R F$ seas}

An experimental data (since 1969) on tritium concentration in precipitations was received. It is approximated a meridian distribution by linear dependence, and latitude - by exponential with the maximum of tritium concentration in a belt of latitude $52^{\circ}-56^{\circ} \mathrm{N}$. The rivers maximum of tritium concentration practically coincides with a site of a spatial maximum of tritium concentration in an atmospheric precipitation. The tritium fall out on territories of the USSR (Russia) are calculated. The tritium drain in the washing Russia seas is estimated; about $70 \%$ of HTO fall out with an atmospheric 
A

Map of monitoring points in Far East Region

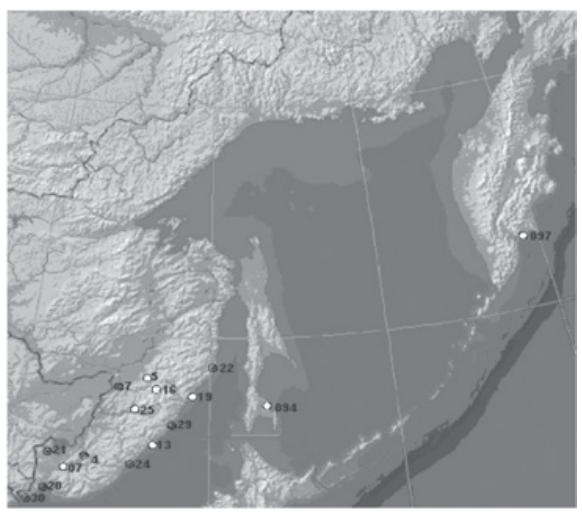

B

Position of ships at the time of precipitations sampling and sampling points on land

B - absense of $3 \mathrm{H}$ anomaly ( $\sigma=8 \mathrm{TU}$ )

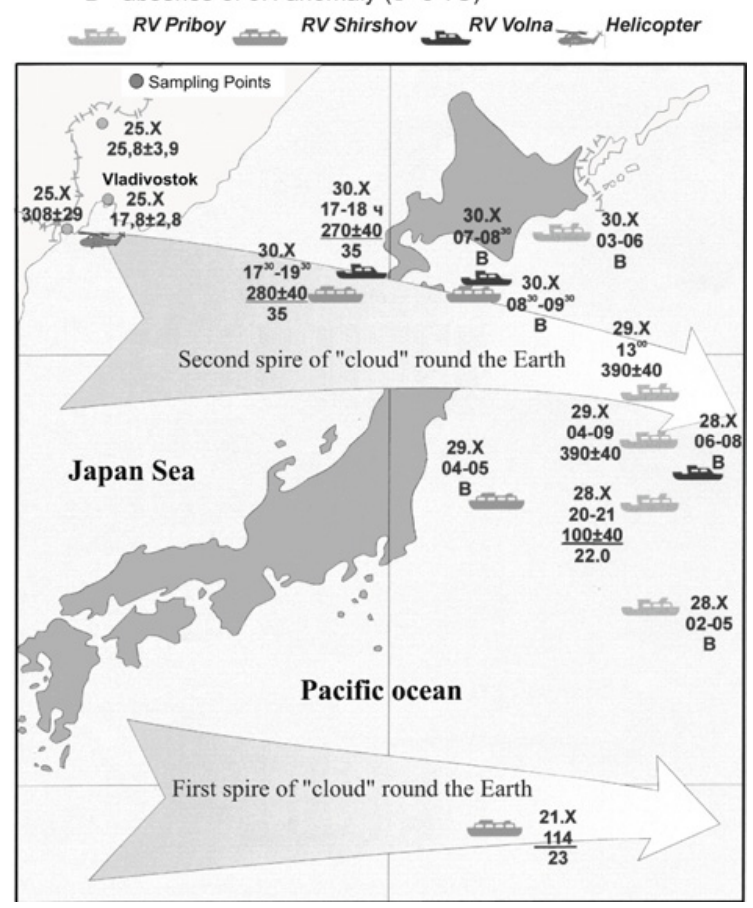

Date shown at the top, Tritium anomaly (TU) in nominator, background HTO in denominator.

Figure 2. A. Tritium monitoring in the Far Eastern Region (1979-1981). B. Scenario of aerosol cloud transfer over North-Western part of the Pacific Ocean.

precipitation on territory of the country flows down in the Arctic seas. The calculation method for balance and entering tritium flow in the sea is offered, and the estimation of tritium stocks and its balance components in Azov, Black, Caspian and Baltic Seas is spent. At accident on Chernobyl AS the basic receipt HTO in atmosphere was short-term and occurred during the moment right after accident and radioecological danger was not represent [1].

\subsubsection{Far east tritium monitoring system of nuclear explosions in the Peoples Republic of China}

For the first time the scientific bases of operative tritium monitoring methodology of nuclear explosions on individual precipitation in separate region have been developed. Experience of application of idea of "mobile range" on water area of the adjoining seas successfully was carried out. Efficiency of tritium monitoring Far East system has been confirmed by tritium anomalies detection (with reliability 0.99), caused by transfer to the region of atmospheric moisture from the Lob Nor range after the last (it occurred 16.10.1980) atmospheric thermonuclear explosions. Ones have been registered in an atmospheric precipitation and a moisture samples by stationary, ship and helicopter complexes for sampling. Passage in the form of two coils round globe in midlatitudes of Northern hemisphere of an aerosol cloud was revealed. Valuable experience for studying of atmospheric transboundary radioactivity transfer was received (fig. 2). 
Hardware-methodical providing of tritium monitoring in Far East region has been introduced in Roshydromet and the Minister of Defense system. Comparison of the developed methodology of HTO monitoring on individual precipitation with sampling of monthly ones on IAEA/WMO networks and some states (the USA, Germany, France, Sweden), shows that its use allows to register more reliably tritium anomalies from local sources and atmospheric transboundary radioactivity transfer.

\section{CONCLUSION}

As a result of model experiments and calculations of the main effects influencing the formation of tritium fields in an atmospheric moisture over ocean and in the basins of underground waters it was shown a prevailing influence of a molecular exchange on the tritium content in the top layer of lakes, the seas and oceans and in an atmospheric moisture over ocean. It has been found the shielding effect of a continent on the tritium content in atmospheric moisture. This phenomenon was used for an estimation of elements of continent water exchange. Priority results of tritium use in the industry (on oil deposits, collieries, mines etc.), and in researches under national and international programs (WESTPAK, SOUTHERN OCEAN, "Isotopes in deposits", the Soviet Arctic and Antarctic expeditions) are received.

On the basis of works of last decade on studying of processes of radioactive pollution transformation of the sea environment in the northern shelf of the Japan Sea there was created the bases of radioactive pollution forecast with HTO use [13].

\section{References}

[1] V. Soyfer et al. "Tritium researches of natural waters in Russia" (GEOS, Moscow, 2008), 286 p. (in Russian)

[2] V. Soyfer. Cruise report IWPAN, IOAN, 1971 (in Russian)

[3] V. Soyfer, et al. Atomic energy, 1980, volume 49 (1980) 303-307 (in Russian)

[4] V.Goryachev, A. Sergeev, V. Soyfer. Second All-Union congress of ocenologists (IOAS, M. 1982) c. 107 (in Russian)

[5] V. Tishkov. Radiochemistry, issue 1(3) - Leningrad: 1979 (in Russian)

[6] F. Alexeev, G. Golbek, V. Soyfer et al (Proc. Int. Conf. IAEA 1960, Vienna, 1960) pp. 519-531

[7] V. Soyfer. Radioactive isotopes and nuclear radiations in a national economy of the USSR, M, 1961, v. 4. (in Russian)

[8] V. Romanov, V. Soyfer. Questions of nuclear geophysics. Proc. AUNGGI. Issue 4, ("Nedra”.M 1968).289-304 (in Russian)

[9] V. Soyfer, S. Denisik, in IV All-Union symposium on geochemistry of stable isotopes, 1972. 106108 (in Russian)

[10] V. Soyfer et al. IV All-Union hydrological congress, Leningrad. (1976) 373-382 (in Russian)

[11] V. Soyfer et al. Applied Radiation and Isotopes Journal, vol. 43, No. 8, (1992) 1041-1044

[12] V. Soyfer et al, DAN USSR, volume 201, No. 1, (1971) 78-81 (in Russian)

[13] V. Soyfer "Radioecology of northern of the Japan Sea shelf". ("Dal'nauka", Vladivostok, 2002) 254+2,6 Quires colour incl. (in Russian) 